\title{
ABSENTEÍSMO NA PERCEPÇÃO DOS DOCENTES DE INSTITUIÇÕES DE ENSINO PÚBLICAS E PRIVADAS
}

\author{
Silvana da Silva Mitri da Costa ${ }^{1}$ \\ Aziz Xavier Beiruth ${ }^{2}$ \\ Lilian Gazzoli Zanotelli ${ }^{3}$
}

\begin{abstract}
RESUMO: Este estudo identificou as diferenças entre os fatores que influenciam a intenção do absenteísmo docente em instituições de ensino públicas e privadas. Para isso utilizou-se construtos adaptados e validados sobre as dimensões psicossociais (engajamento no trabalho, estresse/esgotamento no trabalho, motivação acadêmica e satisfação da carreira) e as dimensões ambientais (conforto térmico, qualidade do ar, iluminação, qualidade acústica, layout da sala de aula, mobiliário, limpeza e manutenção, satisfação geral) na intenção do absenteísmo. Foi realizada uma pesquisa quantitativa, descritiva, com corte transversal, via questionário eletrônico. A amostra final foi constituída por 463 respondentes. Foram estimados os resultados por meio da Regressão Linear Múltipla, com o método Tobit, que indicou a validade do estudo. Nos resultados encontrados, os docentes da rede privada atrelaram sua intenção de ausentar-se do trabalho mais a fatores ambientais, enquanto nas instituições de ensino pública os fatores psicossociais foram priorizados.
\end{abstract}

Palavras-chave: Absenteísmo. Docentes. Instituições de ensino públicas e privadas.

\section{ABSENTEISM IN THE PERCEPTION OF TEACHERS OF PUBLIC AND PRIVATE EDUCATION INSTITUTIONS}

ABSTRACT: This study identified the differences between the factors that influence the intention of teacher absenteeism in public and private educational institutions. To this end, we used adapted and validated constructs on the

\footnotetext{
${ }^{1}$ Mestre em Administração pela Fucape Business School. Coordenadora do Curso Técnico de Segurança do Trabalho do Instituto Federal de Educação Ciência e Tecnologia do Maranhão Campus Monte Castelo/São Luís. E-mail: silvanamitri@ifma.edu.br

${ }^{2}$ Doutor em Controladoria e Contabilidade pela Faculdade de Economia, Administração e Contabilidade da USP. Professor Associado III e Coordenador de Graduação da Fucape Business School. E-mail: azizbeiruth@usp.br

${ }^{3}$ Mestre em Administração pela Fucape Business School. E-mail: liliangazzoli@yahoo.com.br
} 
psychosocial dimensions (work engagement, stress / exhaustion at work, academic motivation and career satisfaction) and environmental dimensions (thermal comfort, air quality, lighting, acoustic quality, classroom, furniture, cleaning and maintenance, general satisfaction) in the intention of absenteeism. A quantitative, descriptive, cross-sectional study was conducted using an electronic questionnaire. The final sample consisted of 463 respondents. The results were estimated through Multiple Linear Regression using the Tobit method, which indicated the validity of the study. In the results found, the teachers of the private network linked their intention to absent themselves of the work more to environmental factors, whereas in the institutions of public education the psychosocial factors were prioritized.

Keywords: Absenteeism. Teachers. Public and private education institutions.

\section{AUSENTISMO EN LA PERCEPCIÓN DE LOS DOCENTES DE INSTITUCIONES DE EDUCACIÓN PÚBLICAS Y PRIVADAS}

RESUMEN: Este estudio identificó las diferencias entre los factores que influyen en la intención del ausentismo docente en las instituciones educativas públicas y privadas. Para esto, utilizamos construcciones adaptadas y validadas sobre las dimensiones psicosociales (compromiso laboral, estrés / agotamiento en el trabajo, motivación académica y satisfacción profesional) y las dimensiones ambientales (confort térmico, calidad del aire, iluminación, calidad acústica, aula, mobiliario, limpieza y mantenimiento, satisfacción general) en la intención de absentismo. Se realizó una encuesta transversal cuantitativa y descriptiva a través de un cuestionario electrónico. La muestra final consistió en 463 encuestados. Los resultados se estimaron utilizando la regresión lineal múltiple con el método Tobit, que indicó la validez del estudio. En los resultados encontrados, los docentes de la escuela privada vincularon más su intención de estar ausentes del trabajo con factores ambientales, mientras que en las instituciones educativas públicas se priorizaron los factores psicosociales.

Palabras clave: Absentismo. Maestros. Instituciones educativas públicas y privadas.

\section{Introdução}

Durante as últimas décadas, a literatura tem indicado que a falta no trabalho vem crescendo gradativamente, tornando-se um processo dispendioso para as organizações (PITKOFF, 1993). O absenteísmo é considerado um fenômeno de etiologia multifatorial, correspondendo à falta de assiduidade ao trabalho, incluindo 
dimensões psicossociais e ambientais (ANDRADE et al., 2008; RODRIGUES et al., 2013). Estudos referentes ao absenteísmo na área educacional evidenciam características próprias causadoras de estresse e de alterações comportamentais dos docentes, em decorrência da tensão do ambiente escolar e de cobranças institucionais (SILVA; CAVEIÃO, 2016). De acordo com a eficiência e a produtividade organizacional, absenteísmo docente é considerado entre as maiores taxas quando comparado a outras profissões (PITKOFF, 1993).

Segundo a Confederação Nacional dos Trabalhadores em Educação (CNTE), em 2013 aproximadamente $20 \%$ dos professores foram afastados do processo produtivo, fora da sala de aula, em virtude de licenças médicas (SILVA; CAVEIÃO, 2016). E, de acordo com Andrade et al. (2008), o absenteísmo é uma realidade brasileira tanto para as instituições públicas quanto para privadas, que acaba impactando muito fortemente na qualidade do ensino, o que compromete a formação do capital humano. Diante deste cenário, foram realizados estudos em instituições públicas de ensino, nos quais foram identificados fatores preditores da intenção do absenteísmo em docentes, que lecionavam para o ensino fundamental em escolas de Israel. Os antecedentes psicossociais referem-se aos autos-relatos desses docentes sobre suas reações emocionais e afetivas e sobre dimensões ambientais de outros profissionais frente ao seu local de trabalho (SHAPIRA-LISHCHINSKY; ISHAN, 2013; KIM et al., 2013). Já em estudos na área da saúde pública e privada, foram observadas semelhanças e diferenças significativas referentes às ausências no trabalho de profissionais de enfermagem tais como, sobrecarga de trabalho, cansaço físico e emocional, representando entre estes os fatores mais comuns de ambas as esferas institucionais na intenção de absenteísmo destes profissionais (FURLAN; STANCATO, 2013).

Entretanto, faz-se necessário investigar na literatura as diversidades do absenteísmo em escolas públicas e privadas em contextos diversos, junto com os antecedentes da intenção de absenteísmo nos diferentes níveis de ensino, como fundamental, médio e superior (OLIVEIRA et al., 2016; MGONJA, 2017; OST; SCHIMAN, 2017; STADLER et al., 2017). Além disso, torna-se importante ampliar os estudos também para a esfera privada de ensino, contribuindo assim para uma comparação dos resultados nos setores educacionais públicos (SHAPIRA-LISHCHINSKY; ISHAN, 2013; GUERRERO et al., 2013; SHAPIRA-LISHCHINSKY; RAFTAR-OZERY, 2016). 
Investigar as dimensões psicossociais e ambientais da intenção do absenteísmo dos docentes ajuda a entender o que motiva estes professores e, ao mesmo tempo, o que os diferenciam quando atuam em diferentes cenários públicos e privados. Assim, considerando ser o absenteísmo um enigma pessoal e dispendioso, este trabalho vem contribuir academicamente comparando as variáveis relativas do absenteísmo docente de diferentes níveis educacionais (fundamental, médio e superior) e esferas de ensino (pública e privada) em países emergentes (SHAPIRA-LISHCHINSKY; ISHAN, 2013; GARRICK et al., 2014; OLIVEIRA et al., 2016; SHAPIRA-LISHCHINSKY; RAFTAROZERY, 2016). Diante do contexto apresentado, esta pesquisa visa responder ao seguinte problema: Quais fatores influenciam a intenção do absenteísmo docente em instituições de ensino públicas e privadas? Para responder esta pergunta, se propõe a cumprir o seguinte objetivo: identificar as diferenças entre os fatores que influenciam a intenção do absenteísmo docente em instituições de ensino públicas e privadas, visto que tal comparação já foi estudada com profissionais da área da saúde pública e privada.

Para atingir o objetivo dessa pesquisa, inicialmente foi realizada uma revisão da literatura relacionando a intenção do absenteísmo (SHAPIRA-LISHCHINSKY; ISHAN, 2013) de docentes de instituições públicas e privadas de ensino (fundamental, médio e superior), com as dimensões psicossociais: engajamento no trabalho (ROOF, 2014), esgotamento/estresse no trabalho (JONES III; NORMAN; WIER, 2010), motivação acadêmica e auto eficácia (VECCHIONE; ALESSANDRI; MARISCANO, 2014) e satisfação na carreira (SPURK; ABELE; VOLNER, 2011), além das dimensões ambientais: conforto térmico, qualidade do ar, iluminação, qualidade acústica, layout da sala de aula, mobiliário da sala de aula, limpeza e manutenção, satisfação geral (KIM et al., 2013), que foram adaptadas da literatura. Em seguida foi realizada uma pesquisa quantitativa descritiva com corte transversal, com professores destas instituições. Para pesquisa foi aplicado um questionário eletrônico, no qual foram coletados dados de 463 respondentes.

Como contribuição prática, a pesquisa busca investigar os antecedentes específicos da intenção de absenteísmo dos professores. Contribui também em auxiliar e prever tais atitudes para diferenciá-las, valorizando e identificando os motivadores do absenteísmo, tanto em instituições públicas quanto privadas, no cenário brasileiro 
de ensino (SHAPIRA-LISHCHINSKY; ISHAN, 2013; GARRICK et al., 2014; SHAPIRALISHCHINSKY; RAFTAR-OZERY, 2016). Diante disso, torna-se importante estudar as dimensões econômicas na intenção de absenteísmo destes docentes. Além de comparar os resultados encontrados na pesquisa dos setores públicos e privados em países desenvolvidos com países em desenvolvimento (SHAPIRA-LISHCHINSKY; ISHAN, 2013; GUERRERO, et al., 2013; SHAPIRA-LISHCHINSKY; RAFTAR-OZERY, 2016). O reconhecimento de tais elementos beneficiará na gestão dos professores, dentro das particularidades de cada esfera institucional de ensino, possibilitando intervenções precoces e o desenvolvimento de programas de qualidade de vida no trabalho. Para tanto, no Brasil, pesquisas têm demonstrado que os docentes representam em torno de dois milhões de trabalhadores, os quais têm sido acometidos por patologias, comprometendo o desempenho de suas atribuições, alterando assim, na formação do capital humano (SILVA; CAVEIÃO, 2016).

\section{Fundamentação teórica}

\section{Intenção de Absenteísmo}

O termo absenteísmo significa ausência do empregado no trabalho e esta prática tornou-se prejudicial para as organizações no que se refere a perdas de produtividade, gerando impactos psicológicos no trabalho (GUIMARÃES et al., 2016). A ausência no trabalho pode ser considerada como uma forma de afastamento de situações e ambientes indesejáveis, prejudicando o cumprimento de atividades laborais e a satisfação no trabalho (PORTO, 2016). O absenteísmo pode ser entendido como uma condição que representa a ausência no trabalho, sendo classificado entre elas como absenteísmo voluntário, sendo este definido por razões particulares não justificadas (CERIBELI; OLIVEIRA; SILVA, 2017).

Esta pesquisa vem investigar como a intenção do absenteísmo voluntário é percebida pelos docentes de instituições de ensino públicas e privadas e influenciada pelas dimensões psicossociais e ambientais nos diferentes níveis de ensino (SHAPIRALISHCHINSKY; ISHAN, 2013; ROOF, 2014; JONES III; NORMAN; WIER, 2010; KIM et al., 2013; VECCHIONE; ALESSANDRI; MARISCANO, 2014; SPURK; ABELE; VOLNER, 2011). Tais dificuldades proporcionam uma sobrecarga que poderá prejudicar a saúde destes trabalhadores, ocasionando um desgaste físico, psicológico, social e espiritual, além 
destes também podem ser considerados como antecedentes os conflitos familiares ocorrendo simultaneamente com o trabalho (SHAPIRA-LISHCHINSKY; ISHAN, 2013; PORTO, 2016). Nos países em desenvolvimento, o absenteísmo representa um problema relacionado aos fatores psicossociais e individuais. Estes impactam na assiduidade dos professores, causando reflexos na produtividade e também na qualidade do serviço ofertado. Tais impactos servem assim, como indicador das condições do trabalho, da qualidade de vida e das relações trabalhistas dos docentes (GUERRERO et al., 2013; KIM et al., 2013).

\section{Fatores que influenciam o absenteísmo}

De acordo com a literatura, os fatores que influenciam a intenção do absenteísmo estão relacionados às dimensões psicossociais e ambientais (SHAPIRALISHCHINSKY; ISHAN, 2013; KIM et al., 2013). Sendo que, as dimensões psicossociais referem-se aos relatos dos profissionais sobre suas reações afetivas e emocionais presentes no ambiente de trabalho (LEKA et al., 2011). E as dimensões ambientais aludem às reações do trabalhador frente ao ambiente físico de trabalho (KIM et al., 2013).

\section{Dimensões psicossociais}

\section{a) Engajamento no trabalho}

O engajamento é definido como um estado de espírito positivo, satisfatório, relacionado ao trabalho, caracterizado por vigor, dedicação, absorção e também como mediador da relação entre os recursos de trabalho e do volume de trabalho (ROOF, 2014). Verificou-se na literatura que o engajamento no trabalho identifica o quanto um empregado se dedica, ou se relaciona no seu ambiente laboral (ROOF, 2014). Constatou-se em estudos anteriores, que trabalhadores engajados são mais capazes de criar seus próprios recursos de trabalho do que aqueles com baixa participação (ROOF, 2014). Tendo um melhor senso de conexão energética e eficácia em suas atividades laborais, apresentando-se mais capacitados para lidar com as demandas de trabalho (BAKKER; BAL, 2010). Este estudo visa identificar se o fator engajamento no trabalho influencia na intenção de absenteísmo dos docentes de instituições de ensino públicas e privadas. 


\section{b) Esgotamento/estresse no trabalho}

O estresse é definido como uma tensão negativa que é caracterizada pelo desalinhamento entre as exigências da função de desempenho e dos recursos para o desempenho de uma tarefa. Diante disso, estressores psicossociais, tanto relacionados a natureza de suas funções, quanto ao contexto social e familiar e aos recursos para corresponder as tais exigências, estão atingindo os docentes, colocando assim em risco seu bem-estar (JONES III; NORMAN; WIER, 2010). O estresse no ambiente laboral é pertinente a cobranças e pressões que o trabalhador se aflige. Estas por sua vez, tornam-se fatigantes e danosas ao trabalhador por não estarem compatíveis aos seus saberes, habilidades e competências (GARRICK et al., 2014). Pesquisas anteriores intensificam atenção aos potenciais efeitos do estresse num amplo conjunto de ocupações e profissões, explorando os antecedentes e os resultados, tanto para os indivíduos quanto as empresas em conviver com os efeitos negativos deste, gerados pelo desgaste do trabalho, proporcionando um estilo de vida não saudável (JONES III; NORMAN; WIER, 2010). Na presente pesquisa, pretende-se identificar se o estresse no trabalho interfere na intenção de absenteísmo dos docentes de instituições de ensino públicas e privadas.

\section{c) Motivação acadêmica}

A motivação é um fenômeno altamente complexo, que influencia e é influenciado por um número de fatores no ambiente organizacional. Tal motivação também é considerada um impulso dentro do indivíduo que torna necessário para direcionar as ações e comportamentos das pessoas na realização de metas, focalizando na satisfação de necessidades e expectativas (BASSY, 2002). Em estudos anteriores, foram evidenciados os principais antecedentes de escolaridade (status socioeconômico, inteligência). Estes têm um papel preditivo da motivação intrínseca, de regulação externa de alunos, o qual tem sido investigado em diferentes níveis educacionais, desde o ensino fundamental até a universidade (VECCHIONE; ALESSANDRI; MARSICANO, 2014). Esta pesquisa pretende identificar se a motivação dos docentes no desempenho de suas atividades interfere na intenção de absenteísmo em instituições de ensino públicas e privadas.

d) Satisfação na carreira 
Para obter o sucesso profissional, existem diferentes formas de comportamento e bem-estar, que está atrelado à carreira, envolvendo a proatividade, o clima de aprendizagem organizacional, a auto gerência, a mobilidade, a afetividade positiva e a satisfação de profissional (SPURK; ABELE; VOLMER, 2011). Isso significa que o trabalhador deverá estar envolvido, comprometido com a organização e aberto a mudanças quanto á capacitação estrutural. Assim, a baixa produtividade e a insatisfação profissional influenciam no crescimento do absenteísmo (LASCHINGER et al., 2004). Esta pesquisa pretende identificar se a satisfação na carreira profissional dos docentes interfere na intenção do absenteísmo em instituições de ensino públicas e privadas.

\section{Dimensões Ambientais}

\section{a) Conforto térmico}

Considera-se conforto térmico como a temperatura ideal ou confortável no ambiente de trabalho, satisfazendo assim a maioria dos ocupantes deste local (LEUCZ, 2001; KIM et al., 2013). A temperatura é considerada como um ponto relevante no ambiente laboral, devendo proporcionar sensações de conforto térmico, enquanto outras, por serem excessivamente elevadas ou baixas, tornam-se desagradáveis (KIM et al., 2013). Em seus estudos Kim et al. (2013), demonstraram que em determinados ambientes de trabalho, o conforto térmico pode ser considerado satisfatório para uns e não satisfatório para outros. Aliados a este contexto, a temperatura ambiental, quando desconfortável, torna-se prejudicial à saúde do trabalhador gerando acidentes, que afetam o desempenho e a produtividade organizacional, tanto de elementos culturais de construção do conhecimento como na formação do capital humano (LEUCZ, 2001; KIM et al., 2013). Nesta pesquisa pretende-se identificar se o conforto térmico no ambiente laboral dos docentes interfere na intenção do absenteísmo em instituições de ensino públicas e privadas.

\section{b) Qualidade do ar}

A qualidade do ar refere-se ao bem-estar do ser humano no seu habitat e para ser mensurada, considera-se a quantidade de partículas existentes em suspensão no $\operatorname{ar}($ KIM et al., 2013). A taxa de renovação das partículas no ar decorre da natureza de 
cada atividade nociva ou não, sendo mais intensa nos locais considerados poluidores (LEUCZ, 2001). Os malefícios que são causados pelo ar poluído, pela umidade e pela falta de ventilação no ambiente laboral são preocupantes, pois comprometem a saúde física e mental do trabalhador. Estas reações influenciam no comportamento humano e desempenho organizacional (FINNA; FORGACS, 2010). A interdependência entre as pessoas e o ambiente organizacional, está associada à má qualidade do ar interior, aos problemas de iluminação, ao desconforto térmico e também às lesões ocupacionais (KIM et al., 2013).

Diante deste contexto, os estudos revelam que as alterações no ar podem afetar sua qualidade percebida no ambiente laboral (HONGISTO et al., 2016). Dentre estas, destacam-se o cheiro de cigarro, o cheiro da comida, o cheiro do café, a quantidade de poeiras e sujeiras nas estações de trabalho, o cheiro de móveis antigos, o cheiro de mofo pelo acúmulo de papéis velhos e demais cheiros adversos (HONGISTO et al., 2016). Esta pesquisa pretende identificar se a qualidade do ar no ambiente laboral dos docentes interfere na intenção do absenteísmo em instituições de ensino públicas e privadas.

\section{c) Iluminação}

A luz é o agente da visão, sendo esta enviada aos olhos para visualizar um corpo, e um ambiente mal iluminado ocasiona cansaço nos olhos, resultando em dores de cabeça, irritação e estresse (VISCHER, 2007; KIM et al., 2013). Com isso, a iluminação de interiores busca preencher de luz artificial os locais fechados, dosando para isso, entre o belo e o conforto iluminante para os olhos. Problemas de iluminamento podem ser decorrentes do mau dimensionamento na iluminação do ambiente laboral (FINNA; FORGACS, 2010). Com isso, as cores contribuem para melhorias das condições físicas do trabalho, adaptando o homem ao seu posto de trabalho. O ser humano reage às cores, podendo ficar triste, alegre, calmo ou até estressado (LEUCZ, 2001; FINNA; FORGACS, 2010). Esta pesquisa pretende identificar se a iluminação no ambiente laboral dos docentes interfere na intenção do absenteísmo em instituições de ensino.

\section{d) Qualidade acústica}

O ruído é uma combinação de diversas vibrações, medido em decibéis, que pode ser considerado como ruído contínuo e intermitente, ou também como ruído de 
impacto. Numa sala de aula para se obter bons resultados acústicos, o nível de ruído deve corresponder entre 30 a 35 decibéis (FINNA; FORGACS, 2010). Além de proporcionar sérios efeitos negativos ao trabalhador, o ruído quando presente no ambiente laboral acaba prejudicando na concentração. Com isso, pode alterar no desempenho do profissional, ocasionando um aumento significativo de número de erros nas suas atividades (LEUCZ, 2001; VISCHER, 2007; FINNA; FORGACS, 2010; KIM et al., 2013).

Em estudos anteriores mostram que os ruídos em locais de trabalho abertos oportunizam altos níveis de distração e perturbações ao trabalhador (VISCHER, 2007; HONGISTO et al., 2016), sendo o ruído um dos fatores mais perturbadores do ambiente interno, devendo ser evitado. Este, caso não consiga ser eliminado, deve-se adotar medidas preventivas a fim de minimizá-lo. Diante do exposto, esta pesquisa pretende identificar se a qualidade acústica no ambiente laboral dos docentes interfere na intenção do absenteísmo em instituições de ensino públicas e privadas.

\section{e) Layout da sala}

Considera-se layout, o arranjo físico dos locais de trabalho e as fronteiras entre estes (KIM; YOUNG, 2014). Tais autores demonstram que as características de layout, tais como: espaços e arranjos entre as estações de trabalho afetam nas percepções e nas atitudes dos trabalhadores. Kim e Young (2014) afirmam ainda, que layout da sala pode reduzir o desempenho, propiciando irritabilidade, gerando com isso insatisfação e estresse. Para que uma instituição de ensino funcione com mais pessoas em menos espaços é necessário que estes sejam otimizados, a fim de sensibilizar as pessoas para que haja uma mudança de cultura organizacional (FINNA; FORGACS, 2010).

Um ambiente, quando bem projetado, pode reduzir as necessidades espaciais de uma instituição, melhorando o gerenciamento de suas atividades e sua eficiência organizacional (KIM; YOUNG, 2014). Para estes autores, fornecer um ambiente aprimorado e agradável proporciona um aumento na produtividade individual, minimizando com isso o absenteísmo e reduzindo custos na formação do capital humano. Esta pesquisa pretende identificar se o layout do ambiente de trabalho dos docentes interfere na intenção do absenteísmo em instituições de ensino públicas e privadas. 


\section{f) Mobiliário da sala}

Segundo Leucz (2001), o mobiliário é um elemento essencial no ambiente laboral. Para Kim e Young (2014) o conforto físico e/ou psicológico dos trabalhadores deve ser prioritário na escolha do mobiliário, pois este pode favorecer ou prejudicar o desempenho no ambiente de trabalho. Para Finna e Forgacs (2010) a adequação do mobiliário visa proporcionar o bem-estar humano com a adoção de ferramentas e utensílios apropriados aos trabalhadores no ambiente laboral. Isto reduz os custos associados às lesões e aos esforços repetitivos. Diante disso, entende-se que situações de desajustes ambientais podem resultar na desmotivação e no absenteísmo no trabalho. Assim, tais desajustes, podem gerar estresse, sendo este influenciado pelo afeto negativo, pela limitação de motivação e pelo desempenho laboral (VISCHER, 2007; KIM et al., 2013). Esta pesquisa pretende identificar se o mobiliário do ambiente de trabalho dos docentes interfere na intenção do absenteísmo em instituições de ensino públicas e privadas.

\section{g) Limpeza e manutenção}

Para Leucz (2001), um local de trabalho, seja um escritório, uma oficina ou uma sala de aula, deve ser sadio e agradável. Contudo, este deve estar atrelado a uma finalidade social de educar, criando ao ser humano, hábitos de higiene, de manutenção e de limpeza (KIM et al., 2013). Para o ser humano, é importante encontrar em seu ambiente de trabalho, condições mínimas de segurança, de proteção e de integridade física que proporcionam satisfação (LEUCZ, 2001; FINNA; FORGACS, 2010). Esta pesquisa pretende identificar se manutenção e limpeza do ambiente de trabalho dos docentes interferem na intenção do absenteísmo em instituições de ensino públicas e privadas.

\section{h) Satisfação geral}

A satisfação no trabalho é definida como a expressão de sentimentos positivos presentes no ambiente laboral. Neste sentido, estudos anteriores demonstram que os locais físicos de trabalho, quando bem projetados, podem agir como um impulso positivo para melhoria do desempenho laboral (KIM; YOUNG, 2014). Aliada a este contexto, a satisfação no trabalho evoca respostas emocionais e estéticas nas 
organizações, trazendo consequências comportamentais, tais como a saúde do trabalhador, comunicação eficaz e redução do absenteísmo (KIM; YOUNG, 2014). Atrelados a isso, um ambiente escolar também deve ser organizado de tal forma que permita a satisfação geral, mantendo condições adequadas de saúde, segurança e conforto dos docentes (LEUCZ, 2001). Esta pesquisa pretende identificar se a satisfação geral no ambiente de trabalho dos docentes interfere na intenção do absenteísmo em instituições de ensino públicas e privadas.

\section{Diferenças nos incentivos entre setor público e privado}

\section{Setor público}

Uma das principais características do setor público é a responsabilidade direta que este possui com a sociedade, redefinindo constantemente sua missão, a fim de entender as mudanças que ocorrem na sociedade mantendo assim, uma conexão direta com seus usuários (LASCHINGER et al., 2004; GUIMARÃES et al., 2016). Para se nortear, a administração pública adota princípios de eficiência e eficácia para obter resultados positivos e satisfatórios, não permitindo apenas o cumprimento de tarefas, mas otimizando ao máximo os resultados (LASCHINGER et al., 2004).

Estudos demonstram que a falta de otimização no serviço público acarreta adversidades no ambiente de trabalho, estas por sua vez, acabam direcionando o trabalhador a constantes faltas, provocando o absenteísmo (LASCHINGER et al., 2004). As faltas voluntárias além de atingirem negativamente o setor público afetam a sociedade, por meio de interrupção de serviços, greves, além de demissões e conflitos (LASCHINGER et al., 2004; GUIMARÃES et al., 2016). Nos Estados Unidos, por exemplo, na Carolina do Norte, o absenteísmo docente é punido por lei estadual, permitindo um quantitativo máximo de faltas. Tais ausências estão relacionadas principalmente a carga horária de trabalho dos professores e ao nível fundamental de ensino que lecionam (OST; SCHIMAN, 2017).

No caso dos servidores públicos, o absenteísmo encontra-se vinculado a estabilidade. Estes, por sua vez, possuem os menores índices de absenteísmo no ambiente de trabalho quando se encontram em estágio probatório, ou seja, 03 anos para serem considerados estáveis (CERIBELI; OLIVEIRA; SILVA, 2017). Já Guerrero et al. 
(2013), identificaram que o absenteísmo docente representa um problema aos alunos, uma vez que este reduz as oportunidades de aprendizado do aluno.

\section{Setor privado}

Os estudos apontam que no setor privado, as principais causas do absenteísmo estão atreladas ao absenteísmo involuntário. Este, por sua vez, gera baixo desempenho, desmotivação, instabilidade e insatisfação do empregado (PORTO, 2016). Sendo assim, o absenteísmo tornou-se alvo de interesse da iniciativa privada a fim de criar ações necessárias para combater suas causas e reduzir perdas econômicas e produtivas (PORTO, 2016). A literatura demonstra que políticas de incentivos vêm ganhando destaque nas organizações para minimizar o absenteísmo no ambiente laboral, melhorando o engajamento no trabalho, a satisfação na carreira e a motivação profissional (CERIBELI; OLIVEIRA; SILVA, 2017). Dentre estes, estão os principais fatores psicossociais que impactam o absenteísmo no ambiente organizacional (LEKA et al., 2011; ARIF; ILYAS, 2013).

Nos estudos realizados com professores de universidades privadas, o engajamento no trabalho, motivação e a satisfação na carreira foram os principais fatores que influenciaram na percepção da qualidade de vida profissional destes docentes (ARIF; ILYAS, 2013). Diante disso, tanto o ambiente laboral quanto os aspectos psicossociais atraem, motivam e mantém os empregados à organização privada (ARIF; ILYAS, 2013). Para Mgonja (2017), em estudos realizados com professores sobre o absenteísmo, indicam que as faltas constantes no trabalho podem levar a demissão, esta, é tratada como uma medida rígida, de falta injustificada com corte de pagamento. Com isso, pode-se inferir que o absenteísmo docente de instituições de ensino privadas pode ser influenciado por dimensões emocionais, sociais e físicas.

\section{Setores públicos e privados}

Ao comparar o absenteísmo no setor público e privado, percebe-se que os servidores públicos são mais propensos as faltas no trabalho do que os trabalhadores do setor privado (CERIBELI; OLIVEIRA; SILVA, 2017). Com isso, as organizações, públicas ou privadas precisam conhecer suas dimensões para assim poder definir políticas e investir em soluções, a fim de obter eficiência e a eficácia organizacional (MIAKE et al., 
2018). Isso proporciona melhorias na produtividade e na qualidade de vida dos trabalhadores (GARRICK et al., 2014; PORTO, 2016; GUIMARÃES et al., 2016).

Estudos revelam que tanto a remuneração e a equidade externa são consideradas pontos críticos de insatisfação de professores de instituições de ensino públicas e privadas. Esta insatisfação do professor no ambiente escolar gera o aumento do absenteísmo (GUIMARÃES et al., 2016). A motivação do professor ao trabalho, apresenta-se menor nas escolas públicas, indicando um aumento do índice de absenteísmo dos professores das escolas públicas em comparação com escolas privadas (CERIBELI; OLIVEIRA; SILVA, 2017).

Entretanto, pesquisas relacionadas às condições de trabalho docente revelam que a satisfação dos professores de escolas privadas é maior do que nas escolas públicas. No que se refere aos fatores psicossociais e ambientais, levando a redução do absenteísmo, principalmente no que se refere ao engajamento no trabalho, redução do stress e possibilidade de crescimento profissional (OLIVEIRA et al., 2016).

\section{Método}

Com o intuito de identificar as diferenças entre os fatores que influenciam a intenção do absenteísmo docente em instituições de ensino públicas e privadas, realizou-se esta pesquisa do tipo descritiva, quantitativa, com corte transversal. A população alvo foram os docentes que lecionam em escolas públicas e privadas nos níveis fundamental, médio e superior, composta por 463 respondentes. A amostra utilizada no estudo foi de caráter não probabilístico, com dados primários.

Para a coleta de dados, foi aplicado um questionário composto por 47 afirmativas, referentes aos construtos (intenção do absenteísmo, engajamento no trabalho, esgotamento /estresse no trabalho, motivação acadêmica, satisfação na carreira, conforto térmico, qualidade do ar, iluminação, qualidade acústica, layout da sala de aula, mobiliário da sala de aula, limpeza e manutenção e satisfação geral). 0 questionário foi disponibilizado aos docentes via plataforma online, no período de novembro a dezembro de 2017. Inicialmente, foram realizadas perguntas de controle no questionário para identificar se o respondente leciona em instituição de ensino, ou seja, se é docente. Para isso foram utilizadas questões referentes ao vínculo docente, tipo de instituição de ensino em que atua; nível de ensino que leciona; carga horária 
contratada e tempo de docência. O primeiro construto mensurado foi à intenção do absenteísmo (SHAPIRA-LISHCHINSKY; ISHAN, 2013) composto por 09 itens.

Em seguida, foram mensuradas as dimensões psicossociais com os construtos: engajamento no trabalho (ROOF, 2014) composto por 09 itens; esgotamento/estresse no trabalho (JONES III; NORMAN; WIER, 2010), composto de 05 itens; motivação acadêmica (VECCHIONE; ALESSANDRI; MARISCANO, 2014), composto de 03 itens e satisfação da carreira (SPURK; ABELE; VOLNER, 2011), composto de 05 itens. Já para mensurar as dimensões ambientais foram utilizados os respectivos construtos sugeridos por Kim et al. (2013): conforto térmico (1 item), qualidade do ar (1 item), iluminação (2 itens), qualidade acústica (2 itens), layout da sala de aula (3 itens), mobiliário da sala de aula (3 itens), limpeza e manutenção (3 itens), satisfação geral (1 item). Todos os construtos foram acompanhados de uma Escala de Likert de 07 pontos para verificar a relação das variáveis.

$\mathrm{Na}$ terceira parte do questionário foram realizadas perguntas referentes à caracterização da amostra (sexo, idade, escolaridade e renda mensal individual), a fim de obter o perfil dos respondentes no estudo. Para validar o questionário foi aplicado um pré-teste em 10 docentes para identificar o entendimento da escala e suas variáveis. Depois de efetivada as correções no questionário, foi realizada a coleta de dados. Finalmente, para análise dos dados, foi utilizado o teste de diferenças de médias em função das instituições de ensino públicas e privadas e a regressão linear múltipla, do tipo Tobit, para validar e testar os construtos mensurados conforme a intenção do absenteísmo no modelo proposto.

\section{Análise dos resultados}

\section{Caracterização da amostra}

A amostra foi composta por 463 respondentes, e verificou as informações sócio demográficas dos docentes de instituições de ensino públicas e privadas. Os resultados revelaram na amostra final, uma maior concentração de docentes de instituições públicas de ensino $(76,5 \%)$, em contrapartida com os resultados das instituições privada que mostraram apenas um quarto da amostra total dos respondentes $(23,5 \%)$. Do total de respondentes, $57,9 \%$ foi do sexo feminino e $42,1 \%$ do masculino. Quanto à idade, a maior parte dos docentes se concentrou na faixa etária entre 26 a 45 anos 
(65,0\%). A maioria da amostra apresentou alta escolaridade $(67,8 \%)$, sendo composta de $36,7 \%$ de especialistas e $31,1 \%$ de mestres. Apenas $1,7 \%$ dos docentes da amostra possuem somente o ensino médio completo, demonstrando assim boa qualificação entre os docentes pesquisados. Em relação à renda mensal individual, houve maior concentração dos respondentes ganhando até $\mathrm{R} \$ 6.000,00$.

Quanto ao nível de ensino que os professores lecionam houve um maior predomínio no ensino médio e médio superior (51,4\%), seguidos de um terço no ensino fundamental (20,3\%). Em relação à carga horária trabalhada, houve maior concentração dos docentes lecionando em 40 horas/semanais com dedicação exclusiva (41,9\%). Houve equidade nos que lecionam com carga horária de até 20 horas/semanais $(18,6 \%)$ e de 31 a 40 horas/semanais (18,4\%). Para a variável, tempo de serviço na docência, 09 professores não responderam esta questão. Portanto a amostra final desta variável contou com 454 respondentes. Assim sendo, a maioria dos professores possuem entre 6 a 15 anos de serviço na docência (38,9\%), e apenas 9,0\% destes, entre 20 a 25 anos de serviço na docência.

\section{Estatística Descritiva}

Nesta etapa do trabalho foram apresentadas as estatísticas descritivas dos construtos utilizados para mensurar as relações entre as variáveis buscando verificar o comportamento dos dados quanto suas posições e dispersões. Segue abaixo o modelo proposto para análise:

$$
\begin{gathered}
Y=\beta 0+\beta 1 \times 1+\beta 2 \times 2+\beta 3 \times 3+\beta 4 \times 4+\beta 5 \times 5+\beta 6 \times 6+\beta 7 \times 7+\beta 8 \times 8+\beta 9 \times 9+ \\
\beta 10 \times 10+\beta 11 \times 11+\beta 12 \times 12)+C+\varepsilon
\end{gathered}
$$

Onde: $Y=$ Intenção do Absenteísmo; $X 1=$ Engajamento no Trabalho; $X 2=$ Esgotamento/Estresse no Trabalho; X3= Motivação Acadêmica e Auto Eficácia; X4= Satisfação Carreira; X5= Conforto Térmico; X6= Qualidade do Ar; X7=Iluminação; X8= Qualidade Acústica; X9= Layout da Sala; X10= Mobiliário da Sala; X11= Limpeza e Manutenção; $X 12=$ Satisfação Geral; $C=$ Controles; $\varepsilon=$ Erro.

O construto Intenção do Absenteísmo obteve média de 4,96 com desvio padrão de 0,98 ficando acima do ponto neutro da escala (4), variando de forma geral com o mínimo de 1,67 e o máximo de 7,00. Isso evidencia indícios de que há intenção de 
absenteísmo pelos docentes pesquisados. Tal resultado corrobora com os estudos sobre reações afetivas, físicas e emocionais dos trabalhadores diante da intenção de absenteísmo no ambiente de trabalho (SHAPIRA-LISHCHINSKY; ISHAN, 2013; LEKA et al., 2011; KIM et al., 2013). O construto Engajamento no Trabalho apresentou a média mais alta de 5,62 e desvio padrão de 1,22, variando com o mínimo de 1,00 e o máximo de 7,00 . Os resultados sugerem que tais docentes se consideram engajados no seu ambiente de trabalho. Isso converge com a literatura, pois indivíduos engajados no trabalho são mais presentes e participativos no ambiente laboral (ROOF, 2014; BAKKER; BAL, 2010).

O construto estresse/esgotamento no trabalho obteve média com 4,89 com desvio padrão de 1,12, variando de forma geral com o mínimo de 1,00 e o máximo de 7,00 . Tais médias indicam que tendem a concordar de que os docentes estão cansados e/ou esgotados, corroborando com as pesquisas que afirmam que o estresse compromete o bem-estar dos trabalhadores no ambiente laboral, proporcionando um impacto negativo no desempenho (JONES III; NORMAN; WIER, 2010). A motivação acadêmica e auto eficácia teve média alta $(5,11)$ entre os construtos da dimensão psicossocial e baixo desvio padrão $(0,65)$, variando de forma geral com o mínimo de 1,00 e o máximo de 7,00. Isso mostra consonância dos docentes os quais concordam de que estão motivados. Ratificando a literatura sobre o direcionamento de ações para alcance de metas e expectativas pessoais e profissionais no trabalho (BASSY, 2002; VECCHIONE; ALESSANDRI; MARSICANO, 2014).

A satisfação na carreira apresentou média alta $(5,11)$ e desvio padrão $(1,34)$, variando com o mínimo de 1,00 e o máximo de 7,00. Isso demonstra que os docentes concordam de que estão satisfeitos com sua carreira. Estes resultados convergem com estudos que se referem à realização profissional, reconhecimento do trabalho, e ao empoderamento laboral para a satisfação na carreira (LASCHINGER et al., 2004; SPURK; ABELE; VOLMER, 2011). O conforto térmico apresentou média de 4,67 com desvio padrão alto de 1,91, variando de forma geral com o mínimo de 1,00 e o máximo de 7,00. O resultado demonstra que os docentes não concordam nem discordam quanto á temperatura da sala de aula. De acordo com a literatura a temperatura ideal e confortável influencia no conforto do ambiente (KIM et al., 2013). A iluminação apresentou média de 4,90 e desvio padrão de 1,78, variando de forma geral com o 
mínimo de 1,00 e o máximo de 7,00. Isto sugere que os docentes tendem a concordar que a luminosidade e cores no ambiente laboral estão adequados. Estes escores, confirmam os estudos sobre a iluminação do ambiente ser um fator necessário para o bem-estar do trabalho (VISCHER, 2007; FINNA; FORGACS, 2010; KIM et al., 2013).

Em relação à qualidade acústica a média se manteve em 4,22 com desvio padrão de 1,78 , variando de forma geral com o mínimo de 1,00 e o máximo de 7,00. Percebeuse neste construto que os docentes em geral, não concordam nem discordam quanto a acústica das salas de aula. Quanto à qualidade do ar obteve-se média de 4,62 com desvio padrão de 1,89 (variando entre o mínimo de 1,00 e o máximo de 7,00), demonstrando que os docentes estão mais para concordar do que discordar quanto a este critério relacionado aos aspectos ambientais do trabalho. Tais resultados convergem com os estudos, os quais mostram que o bem-estar dos trabalhadores está relacionado com a saúde física e mental e no desempenho de suas atribuições no local de trabalho (FINNA; FORGACS, 2010; KIM et al., 2013).

A limpeza e manutenção obtiveram média de 4,73 e desvio padrão de 1,65, com variação geral de mínimo de 1,00 e máximo de 7,00. Este construto representa conformidade entre os docentes que tendem a concordar de que há higiene e segurança no ambiente laboral. Segundo a literatura, um ambiente saudável e higienizado proporciona mais satisfação no trabalho (FINNA; FORGACS, 2010; KIM et al., 2013). Sobre o layout da sala de aula a média obtida foi de 4,47 e desvio padrão de 1,60 , com variação geral de mínimo de 1,00 e máximo de 7,00. 0 resultado sugere que os docentes nem concordam nem discordam quanto à adequação do layout da sala de aula. A eficiência organizacional gera ambientes agradáveis para o trabalho aumentando assim a produtividade (FINNA; FORGACS, 2010; KIM; YOUNG, 2014). Quanto ao mobiliário da sala de aula a média obtida foi de 4,12 com desvio padrão de 1,79 , com variação geral de mínimo de 1,00 e máximo de 7,00. A média das respostas sugere que os respondentes nem concordam nem discordam sobre o padrão do mobiliário. De acordo com a literatura o mobiliário é um elemento fundamental para o bem-estar do trabalhador (FINNA; FORGACS, 2010; KIM et al., 2013).

A satisfação geral apresentou média de 4,84 e desvio padrão de 1,74 , variando entre o mínimo de 1,00 e máximo de 7,00. Isso indica que os docentes tendem a concordar de que estão satisfeitos no seu ambiente de trabalho. Neste sentido, a 
literatura indica que quando os locais físicos são bem projetados, estes podem agir como um impulso positivo para melhoria do desempenho laboral (KIM; YOUNG, 2014). No resultado da pesquisa, todas as médias ficaram acima de 4, conclui-se com isso, que os docentes tendem a concordar com os construtos. A menor média aparece no construto mobiliário da sala $(4,12)$. Comparando-se com os demais construtos, os docentes revelaram menor importância a este quesito diante da intenção de ausentarse no trabalho, mas o considera essencial na pesquisa. Em suma, os resultados indicam que os fatores psicossociais e ambientais influenciam positivamente na intenção de absenteísmo tanto dos docentes de instituições públicas quanto privadas.

\section{Testes de diferenças de médias em função das instituições de ensino públicas e privadas}

Houve diferenças de médias significativas $(p<0,05)$ para as dimensões psicossociais (engajamento no trabalho e satisfação na carreira) e para as dimensões ambientais (iluminação, qualidade acústica, layout da sala de aula, mobiliário da sala, limpeza e manutenção, satisfação geral, conforto térmico e qualidade do ar (Tabela 1).

Tabela 1 - Teste de diferenças de médias das instituições de ensino públicas e privadas

\begin{tabular}{|c|c|c|c|c|c|c|}
\hline \multirow[b]{3}{*}{ Construtos } & \multicolumn{4}{|c|}{ Instituições de Ensino } & \multirow[b]{3}{*}{$\begin{array}{l}\text { Diferenças } \\
\text { de Médias }\end{array}$} & \multirow[b]{3}{*}{ p-Valor } \\
\hline & \multicolumn{2}{|c|}{ Privadas } & \multicolumn{2}{|c|}{ Públicas } & & \\
\hline & Média & DP & Média & DP & & \\
\hline Intenção de absenteísmo & 5,08 & 1,01 & 4,92 & 0,97 & 0,16 & 0,13 \\
\hline Engajamento & 5,90 & 1,13 & 5,54 & 1,24 & 0,36 & $0,006 * * *$ \\
\hline Estresse/ Esgotamento & 5,06 & 1,17 & 4,83 & 1,10 & 0,23 & $0,062^{*}$ \\
\hline Motivação acadêmica & 5,16 & 0,59 & 5,10 & 0,67 & 0,06 & 0,381 \\
\hline Satisfação na carreira & 4,81 & 1,37 & 5,20 & 1,33 & $-0,39$ & $0,007 * * *$ \\
\hline Iluminação & 5,54 & 1,45 & 4,70 & 1,82 & 0,84 & $0,000 * * *$ \\
\hline Qualidade acústica & 4,80 & 1,70 & 4,04 & 1,77 & 0,76 & $0,000 * * *$ \\
\hline Layout da sala & 5,19 & 1,42 & 4,25 & 1,59 & 0,94 & $0,000 * * *$ \\
\hline Mobiliário da sala & 4,95 & 1,69 & 3,87 & 1,74 & 1,08 & $0,000 * * *$ \\
\hline Limpeza e conservação & 5,45 & 1,38 & 4,51 & 1,66 & 0,94 & $0,000 * * *$ \\
\hline Satisfação geral & 5,51 & 1,43 & 4,63 & 1,78 & 0,88 & $0,000 * * *$ \\
\hline Conforto térmico & 5,18 & 1,53 & 4,52 & 1,99 & 0,66 & $0,001 * * *$ \\
\hline Qualidade do ar & 5,20 & 1,57 & 4,44 & 1,92 & 0,76 & $0,000 * * *$ \\
\hline & $\begin{array}{r}\mathrm{F} \\
\text { Variáve } \\
\text { * Variáv }\end{array}$ & $\begin{array}{l}\text { te: Da } \\
\text { com ní } \\
\text { com r }\end{array}$ & $\begin{array}{l}\text { s da pes } \\
\text { is de sig } \\
\text { vel de sig }\end{array}$ & $\begin{array}{l}\text { disa } \\
\text { ficânci } \\
\text { ficânc }\end{array}$ & $\begin{array}{l}1 \% \\
\%\end{array}$ & \\
\hline
\end{tabular}


Nas dimensões ambientais, observou-se que os docentes de instituições de ensino privado obtiveram as maiores médias em todas as variáveis (iluminação, qualidade acústica, layout da sala de aula, mobiliário da sala, limpeza e manutenção, satisfação geral, conforto térmico e qualidade do ar) comparadas às instituições de ensino públicas, com nível de significância de 1\%, concordando com os estudos realizados em ambientes de empresas privadas (FINNA; FORGACS, 2010; KIM; YONG, 2014). Com isso, mostrou-se que os docentes do ensino privado tendem a perceber mais as dimensões ambientais, já que no setor privado há maiores investimentos em infraestrutura, em relação ao setor público. Já a intenção de absenteísmo, o estresse e a motivação acadêmica não apresentaram diferenças significativas entre os docentes de ensino público e privado. Isso indica que para ambos os docentes a situação de estresse, nível de motivação e intenção de faltar ao trabalho não possuem relevância significativa, nem pertinência quanto a diferenciações no sistema de gestão de pessoas de ambos os setores. Possivelmente, pode haver uma falta de suporte psicoemocional aos docentes tanto de instituições de ensino públicas quanto privadas.

Nas dimensões psicossociais, foram identificadas diferenças de médias significativas nos construtos engajamento no trabalho e satisfação na carreira, com níveis de significância de $1 \%$. No construto engajamento no trabalho houve maior significância de respostas dos docentes vinculados às instituições de ensino privadas. Isso demonstra que os professores do setor privado se preocupam em demasia com seu desempenho no trabalho.

Este resultado corrobora com Roof (2014), mostrando que trabalhadores engajados são mais capazes de criar seus próprios recursos de trabalho. Em contrapartida, o construto satisfação na carreira apresentou maior significância nas instituições de ensino públicas, quando comparado aos docentes das instituições de ensino privadas. Diante deste cenário, este fato pode estar relacionado à estabilidade no trabalho, considerando que no setor público os docentes possuem mais segurança na carreira frente às adversidades do mercado de trabalho. Servidores que ainda não possuem estabilidade se ausentam menos no trabalho (LASCHINGER et al., 2004; GUIMARÃES et al., 2016). 


\section{Análise de regressão modelo Tobit}

Na sequência das análises, foi realizado o teste de regressão Tobit com o objetivo de identificar as diferenças entre os fatores que influenciam a intenção do absenteísmo docente em instituições de ensino públicas e privadas. Este modelo de regressão relaciona o comportamento de uma variável Y (variável dependente) em função da variável $X$ (variável independente), utilizando amostras censuradas ou truncadas (TOBIN, 1958). Nesta pesquisa, considerou-se o modelo de regressão multivariado por ser explicado por mais de uma variável independente. Uma amostra é considerada censurada quando a informação sobre a variável resposta está disponível somente para algumas observações, e truncada quando só se tem um subconjunto de uma população maior de interesse (PINO, 2007).

Neste estudo, foi utilizado o modelo Tobit porque havia duas amostras censuradas, compostas por docentes de instituições de ensino públicas e por docentes de instituições de ensino privadas; e truncadas, pois parte dos questionários enviados não foram respondidos pelos docentes, não se tendo com isso, acesso aos dados de um conjunto maior da população. Utilizando esse modelo foi possível, corrigir os efeitos mensurados.

De acordo com os p-valores dos dados apresentados na Tabela 2, houve correlações significativas nas dimensões psicossociais (engajamento e motivação acadêmica), e no nível de ensino na pós-graduação nos docentes de instituições públicas. Isso indica que tanto o engajamento quanto a motivação acadêmica, influenciam positivamente a intenção do absenteísmo, com 99\% de confiança. Estes resultados apontam que, quanto maiores os valores da escala de Likert destas variáveis (engajamento no trabalho e motivação acadêmica), maior será a intenção do absenteísmo docente, ou seja, professores de ensino público consideram que tanto o engajamento quanto a motivação acadêmica são influenciadores para sua intenção de ausentar-se no trabalho. Além disso, profissionais engajados e motivados esperam que seus colegas atinjam seu mesmo grau de comprometimento; porém, quando suas expectativas não são atendidas, há a maior tendência ao absenteísmo.

Entretanto, as relações para o nível de ensino em que os professores lecionam foram negativas, ou seja, quanto mais o docente se distancia do ensino na pósgraduação (menor o grau de ensino em que leciona), maior será a intenção de se 
ausentar do trabalho (OST; SCHIMAN, 2017). O ensino em maiores níveis de aprendizado abrange alunos com maior maturidade, facilitando a tarefa dos professores ao lidar com estes discentes, diminuindo com isso sua intenção de faltar ao trabalho. Os resultados encontrados corroboram com os estudos em escolas norteamericanas sobre o absenteísmo docente estar atrelado a lecionar em menores níveis de ensino (OST; SCHIMAN, 2017).

Tabela 2 - Resultados da regressão modelo Tobit

\begin{tabular}{|c|c|c|c|c|}
\hline \multirow{3}{*}{ Variáveis } & \multicolumn{4}{|c|}{ Intenção de Absenteísmo } \\
\hline & \multicolumn{2}{|c|}{ Instituições Privadas } & \multicolumn{2}{|c|}{ Instituições Públicas } \\
\hline & Coeficiente & p-valor & Coeficiente & p-valor \\
\hline Engajamento & 0,1445 & 0,096* & 0,2214 & $0,000 * * *$ \\
\hline Estresse & 0,3614 & $0,001 * * *$ & 0,8000 & $0,097^{*}$ \\
\hline Motivação acadêmica & $-0,1840$ & 0,283 & 0,3450 & $0,000 * * *$ \\
\hline Satisfação na carreira & $-0,0633$ & 0,506 & 0,3315 & 0,521 \\
\hline Iluminação & 0,4349 & 0,691 & 0,3784 & 0,416 \\
\hline Qualidade acústica & $-0,6673$ & 0,342 & $-0,2070$ & 0,650 \\
\hline Layout da sala & 0,1684 & 0,250 & $-0,0040$ & 0,939 \\
\hline Mobiliário da sala & 0,2540 & $0,068 *$ & $-0,3903$ & 0,360 \\
\hline Limpeza e conservação & $-0,2452$ & $0,022 * *$ & 0,0064 & 0,897 \\
\hline Satisfação geral & $-0,2456$ & $0,070^{*}$ & $-0,0393$ & 0,376 \\
\hline Conforto térmico & $-0,1203$ & 0,187 & 0,0111 & 0,776 \\
\hline Qualidade do ar & 0,1423 & $0,045 * *$ & $-0,0084$ & 0,860 \\
\hline Sexo & $-0,2547$ & 0,208 & 0,1936 & $0,057^{*}$ \\
\hline Idade & $-0,3953$ & 0,705 & 0,0702 & 0,287 \\
\hline Escolaridade & $-0,0227$ & 0,805 & $-0,0932$ & 0,243 \\
\hline Renda mensal & 0,1408 & $0,037^{* *}$ & 0,0382 & 0,451 \\
\hline \multicolumn{5}{|l|}{ Nível de ensino que leciona: } \\
\hline Médio & $-0,9321$ & 0,803 & 0,1507 & 0,394 \\
\hline Médio e Superior & $-0,3430$ & 0,380 & 0,2065 & 0,266 \\
\hline Superior & $-0,2129$ & 0,475 & 0,2458 & 0,298 \\
\hline Superior e Pós-graduação & $-0,3739$ & 0,254 & 0,1460 & 0,640 \\
\hline Pós-graduação & $-0,1463$ & 0,738 & $-1,6299$ & $0,000 * * *$ \\
\hline Outro & 0,2848 & 0,353 & 0,1259 & 0,566 \\
\hline Carga horária & $-0,4353$ & 0,468 & 0,0240 & 0,614 \\
\hline Tempo de serviço & $-0,5345$ & 0,360 & $-0,0685$ & $0,054^{*}$ \\
\hline Constante & 4,4715 & 0,000 & 1,4856 & 0,003 \\
\hline & $\begin{array}{l}\text { Fonte: Dado } \\
\text { Variáveis co } \\
\text { Variáveis cor }\end{array}$ & $\begin{array}{l}\text { pesquisa a } \\
\text { íveis de sign } \\
\text { ível de signi }\end{array}$ & $\begin{array}{l}\text { da. } \\
\text { ncia } 1 \% \\
\text { cia } 5 \%\end{array}$ & \\
\hline
\end{tabular}


No ensino privado, a análise Tobit (Tabela 2) indicou que há uma maior significância para o estresse, limpeza, qualidade do ar e renda mensal. Contudo, o estresse e a renda mensal demonstraram correlações positivas associadas à intenção do absenteísmo entre docentes de instituições de ensino privadas. Este cenário mostra que estes professores consideram os altos níveis de estresse como fatores determinantes para ausentar-se do seu ambiente laboral, mesmo tendo uma elevada renda mensal (FINNA; FORGACS, 2010; KIM, YOUNG, 2014; OST; SCHIMAN, 2017). Este resultado confirma os autores citados, tanto nas pesquisas, realizadas em escolas, quanto em empresas privadas, sobre o nível de estresse impactar no desempenho do funcionário e nas faltas ao ambiente de trabalho. Para tais docentes do ensino privado, a renda está relacionada a maior comprometimento institucional, aumentando com isso o estresse e, consequentemente levando ao absenteísmo. Para a limpeza, os resultados demostraram relações negativas com a intenção de absenteísmo, ou seja, quanto mais limpo o ambiente, menos desejo de ausentar-se do trabalho (KIM, et al., 2013).

Nas regressões Tobit, tanto para as instituições de ensino públicas, quanto para as privadas, os coeficientes de determinação da regressão (pseudo r2) apresentaram valores baixos, sendo (pseudo $2=0,0876$ ) para as públicas e (pseudo $r 2=0,1712$ ) para as privadas. Estes valores indicaram a porcentagem da variação dos dados que é explicada pelo modelo proposto. Tendo para a primeira regressão (instituições de ensino públicas) $9 \%$ de explicabilidade (pseudo $r 2=0,0876$ ), e para a segunda regressão (instituições de ensino privadas), 17\% de explicabilidade (pseudo $r 2=$ $0,1712)$. Estes resultados revelaram que $17 \%$ do total de associações realizadas entre os construtos do modelo foram significativas para as instituições de ensino privadas e apenas $9 \%$ significativas para as públicas.

Em síntese, os resultados apontaram que, quando comparados, não houve diferenças na intenção de absenteísmo dos docentes de instituições de ensino públicas e privadas. Sendo estas diferenças evidenciadas apenas quando os docentes especificam os antecedentes que levam sua intenção de ausentar-se do trabalho, seja estes motivos associados as dimensões psicossociais ou ambientais de cada instituição de ensino (OLIVEIRA et al., 2016; CERIBELI; OLIVEIRA; SILVA, 2017),

Tais achados divergem da literatura ao comparar a intenção do absenteísmo no 
setor público e privado, pois segundo Ceribeli, Oliveira e Silva (2017), os servidores públicos tendem a ter mais faltas no trabalho do que os trabalhadores do setor privado. Entretanto, convergem com os estudos sobre as diferenças dos antecedentes do absenteísmo em instituições públicas e privadas (KIM et al., 2013; CERIBELI; OLIVEIRA; SILVA, 2017). Como demonstrado, por exemplo nos estudos sobre motivação acadêmica de professores de escolas públicas, os quais impactam diretamente na intenção de absenteísmo (CERIBELI; OLIVEIRA; SILVA, 2017). Assim como pesquisas realizadas em empresas privadas mostrando os efeitos dos fatores ambientais, como qualidade do ar e limpeza influenciando na intenção de ausentar-se do trabalho (KIM et al., 2013).

\section{Conclusão}

Este estudo pretendeu identificar as diferenças entre os fatores que influenciam a intenção do absenteísmo docente em instituições de ensino públicas e privadas. Dentre os resultados encontrados, as dimensões ambientais se destacaram (limpeza e manutenção e a qualidade do ar) na rede privada para combater as faltas no trabalho. Contrastando com os resultados obtidos dos docentes da rede pública que enfatizaram os fatores psicossociais (engajamento no trabalho e motivação acadêmica) para justificar suas ausências laborais.

Dentro do ensino público, a motivação acadêmica e o engajamento no trabalho contribuíram para a intenção de absenteísmo. Entretanto o fato destes professores lecionarem em turmas de pós-graduação minimiza a intenção do absenteísmo docente. Tratando-se ainda das dimensões psicossociais, porém no ensino privado, somente o estresse/esgotamento foi relevante para os docentes. Para o ensino privado, o estresse/esgotamento, a limpeza e manutenção, a qualidade do ar e a renda mensal contribuíram para a intenção dos docentes em ausentar-se no trabalho. Por sua vez, a satisfação na carreira e a intenção de absenteísmo não se diferiram entre os docentes de ambos os setores.

O estudo indica como contribuições teóricas, que os antecedentes do absenteísmo docente tendem a ser divergentes entre as instituições de ensino públicas e privadas, embora a intenção de ausentar-se do local de trabalho não seja expressiva para ambos os docentes destas. O estudo fornece indícios dos fatores que levam os 
docentes à assiduidade ou ausência no trabalho. Tais indicadores podem ser úteis enquanto ferramentas para reforçar a permanência dos trabalhadores em seus ambientes laborais. Assim sendo, esta pesquisa poderá contribuir para uma melhoria na política de gestão de pessoas de instituições de ensino públicas e privadas, nas tomadas de decisões no que se refere a políticas motivacionais. Adotando para isso, princípios eficientes e eficazes que possam direcionar os docentes na obtenção de resultados positivos e satisfatórios, intensificando assim, a formação do capital humano.

Como limitação deste estudo, identificou-se o uso de construtos adaptados, não sendo específicos para investigação da intenção do absenteísmo docente. Sugere-se com isso, que a pesquisa seja testada com outros construtos a fim de ampliar a amostra e comparar resultados. Cabe ressaltar que a amostra foi encaminhada majoritariamente aos institutos federais, o que pode caracterizar certas limitações. Para isso, sugere-se o desenvolvimento de escalas específicas sobre o tema abordado. Para futuros estudos, propõe-se um aprofundamento das percepções dos docentes, buscando ampliar os antecedentes da intenção do absenteísmo no trabalho, como fatores econômicos por exemplo. Também se sugere investigar as características dos respondentes quanto à regionalidade a fim de identificar diferenças culturais e relacioná-las com os resultados das percepções já encontradas, podendo posteriormente traçar um perfil entre estes docentes. Recomenda-se ainda, a realização de uma pesquisa longitudinal com abordagem qualitativa, para verificar possíveis oscilações quanto às intenções de absenteísmo entre os professores do ensino público e privado.

\section{Referências}

ANDRADE, Tania Bof et al. Prevalência de absenteísmo entre trabalhadores do serviço público. Scientia Médica, v. 18, n. 4, p. 166-171, 2008.

ARIF, Seema; ILYAS, Maryam. Quality of work-life model for teachers of private universities in Pakistan. Quality Assurance in Education, v. 21, n. 3, p. 282-298, 2013. 
BAKKER, Arnold B.; BAL, Matthijs P. Weekly work engagement and performance: A study among starting teachers. Journal of Occupational and Organizational Psychology, v. 83, n. 1, p. 189-206, 2010.

BASSY, Maren. Motivation and work-Investigation and analysis of motivation factors at work. Li.u - Linköping University. Department of Management and Economics. Swedish, 2002.

CERIBELI, Harrison Bachion; OLIVEIRA Inácio Raoni; SILVA, Mara Cristina. Uma análise do absenteísmo no setor público brasileiro. Revista Acadêmica São Marcos, v. 6, n. 2, p. 2-20, 2017.

FINNA, Henrietta; FORGACS, Tamas. Enhancement of human performance with developing ergonomic workplace environment and providing work-life balance. Perspectives of Innovations, Economics and Business, v. 5, n. 2, p. 59-61, 2010. FURLAN, Jussara Aparecida da Silva S.; STANCATO, Katia. Fatores geradores do absenteísmo dos profissionais de enfermagem de um hospital público e um privado. Rev. Adm. Saúde, v. 15, n. 60, p. 111-120, 2013.

GARRICK, Adam et al. Prevalence and organisational factors of psychological injury among Australian school teachers. The Australasian Journal of Organisational Psychology, v. 7, 2014.

GUERRERO, Gabriela et al. Getting teachers back to the classroom. A systematic review on what works to improve teacher attendance in developing countries. Journal of Development Effectiveness, v. 5, n. 4, p. 466-488, 2013.

GUIMARÃES, Grazielly Fagundes Magnago et al. Absenteísmo no setor público: um estudo de caso no Espírito Santo. Revista Intelletto, v.1, n.1, 2016 p. 15-23, 2016.

HONGISTO, Valtteri et al. Refurbishment of an open-plan office-Environmental and job satisfaction. Journal of environmental psychology, v. 45, 176-191, 2016.

JONES III, Ambrose; NORMAN, Carolyn Strand; WIER, Benson. Healthy lifestyle as a coping mechanism for role stress in public accounting. Behavioral Research in Accounting, v. 22, n. 1, p. 21-41, 2010.

$\mathrm{KIM}$, Jungsoo et al. Gender differences in office occupant perception of indoor environmental quality (IEQ). Building and Environment, v. 70, p. 245-256, 2013.

KIM, Seok Eun; YOUNG, Wesley R. Office Characteristics and Perceived Behavioral Outcomes in a Public Agency: An Empirical Study. Public Performance \& Management Review, v. 38, n. 1, p. 76-99, 2014. 
LASCHINGER, Hearther K. Spence et al. A longitudinal analysis of the impact of workplace empowerment on work satisfaction. Journal of Organizational Behavior, v. 25, n. 4, 527-545, 2004.

LEKA, Stavroula et al. The role of policy for the management of psychosocial risks at the workplace in the European Union. Safety Science, v. 49, n. 4, 558-564, 2011.

LEUCZ, Júlia. Ambiente de trabalho das salas de aula no ensino básico nas escolas de Curitiba. Florianópolis: UFSC, 2001.

MGONJA, Michael Greyson. Responding to Workplace Absenteeism in Tanzania: The case study of Public and Private Schools in Ilala Municipality and Mkuranga District. International Journal of Educational Leadership and Management, v. 5, n. 1, p. 85108, 2017.

MIAKE, Alessandro Henrique de Souza et al. Customer Knowledge Management (CKM): Model Proposal and Evaluation in a Large Brazilian Higher Education Private Group. BBR. Brazilian Business Review, v. 15, n. 2, p. 135-151, 2018.

OLIVEIRA, Tiago Fernandes et al. Qualidade de vida no trabalho: um estudo comparativo entre professores de escola pública e privada. Psicologia Argumento, v. 34, n. 85, 2016.

OST, Ben; SCHIMAN, Jeffrey C. Workload and teacher absence. Economics of Education Review, v. 57, p. 20-30, 2017.

PINO, Francisco Alberto. Modelos de decisão binários: uma revisão. Rev. de Economia Agrícola, v. 54, n. 1, p. 43-57, 2007.

PITKOFF, Evan. Teacher absenteeism: What administrators can do. NASSP bulletin, v. 77, n. 551, p. 39-45, 1993.

PORTO, Ricardo Bersch. Absenteísmo: causas e consequências na organização. Maiêutica-Estudos Contemporâneos em Gestão Organizacional, v. 4, n. 1, 2016.

RODRIGUES, Celeste Souza et al. Absenteísmo-doença segundo autorrelato de servidores públicos municipais em Belo Horizonte. Revista Brasileira de Estudos de População, v. 30, p. 135-154, 2013.

ROOF, Richard A. The association of individual spirituality on employee engagement: the spirit at work. Journal of Business Ethics, v. 130, n. 3, p. 585-599, 2014.

SHAPIRA-LISHCHINSKY, Orly; ISHAN, Gamal. Teachers' acceptance of absenteeism: Towards developing a specific scale. Journal of Educational Administration, v. 51, $n$. 5, p. 594-617, 2013. 
SHAPIRA-LISHCHINSKY, Orly; RAFTAR-OZERY, Tehila. Leadership absenteeism acceptance, and ethical climate as predictors of teachers' absence and citizenship behaviors. Educational Management Administration \& Leadership, 2016.

SILVA, Mariana Moreira; CAVEIÃO, Cristiano. Análise dos afastamentos de saúde dos trabalhadores de ensino de Divinópolis-MG. Revista Saúde e Desenvolvimento, v. 10, n. 5, p. 138-156, 2016.

SPURK, Daniel; ABELE, Andrea E.; VOLMER, Judith. The Career Satisfaction Scale: Longitudinal measurement invariance and latent growth analysis. Journal of Occupational and Organizational Psychology, v. 84, n. 2, p. 315-326, 2011.

STADLER, Adriano et al. Study on Professors' Perception With Respect to Higher Education Institutions' Socially Responsible Initiatives. BBR. Brazilian Business Review, v. 14, n. 6, p. 592-608, 2017.

TOBIN, J. Estimation of relationships for limited dependent variables. Econometrica, v. 26, n. 1, p. 24-36, 1958.

VECCHIONE, Michele; ALESSANDRI, Guido; MARSICANO, Gilda. Academic motivation predicts educational attainment: Does gender make a difference?. Learning and Individual Differences, v. 32, p. 124-131, 2014.

VISCHER, Jacqueline $C$. The effects of the physical environment on job performance: towards a theoretical model of workspace stress. Stress and Health, v. 23, n. 3, p. 175-184, 2007. 